\title{
Multiscale Hybrid Micro-Nanocomposites Based on Carbon Nanotubes and Carbon Fibers
}

\author{
Fawad Inam, ${ }^{1}$ Doris W. Y. Wong, ${ }^{2}$ Manabu Kuwata, ${ }^{2}$ and Ton Peijs ${ }^{1,2,3}$ \\ ${ }^{1}$ Nanoforce Technology Limited, Joseph Priestley Building, Mile End Road, London E1 4NS, UK \\ ${ }^{2}$ Centre for Materials Research, School of Engineering and Materials Science, Queen Mary University of London, \\ Mile End Road, London E1 4NS, UK \\ ${ }^{3}$ Eindhoven Polymer Laboratories, Eindhoven University of Technology, P.O. Box 40, 5600 MB Eindhoven, The Netherlands
}

Correspondence should be addressed to Ton Peijs, t.peijs@qmul.ac.uk

Received 30 November 2009; Accepted 16 March 2010

Academic Editor: Frank T. Fisher

Copyright (C) 2010 Fawad Inam et al. This is an open access article distributed under the Creative Commons Attribution License, which permits unrestricted use, distribution, and reproduction in any medium, provided the original work is properly cited.

\begin{abstract}
Amino-modified double wall carbon nanotube (DWCNT-NH ${ }_{2}$ /carbon fiber (CF)/epoxy hybrid micro-nanocomposite laminates were prepared by a resin infusion technique. DWCNT- $\mathrm{NH}_{2}$ /epoxy nanocomposites and carbon fiber/epoxy microcomposites were made for comparison. Morphological analysis of the hybrid composites was performed using field emission scanning electron microscope. A good dispersion at low loadings of carbon nanotubes (CNTs) in epoxy matrix was achieved by a bath ultrasonication method. Mechanical characterization of the hybrid micro-nanocomposites manufactured by a resin infusion process included three-point bending, mode I interlaminar toughness, dynamic mechanical analysis, and drop-weight impact testing. The addition of small amounts of CNTs $(0.025,0.05$, and $0.1 \mathrm{wt} \%)$ to epoxy resins for the fabrication of multiscale carbon fiber composites resulted in a maximum enhancement in flexural modulus by $35 \%$, a $5 \%$ improvement in flexural strength, a $6 \%$ improvement in absorbed impact energy, and 23\% decrease in the mode I interlaminar toughness. Hybridization of carbon fiber-reinforced epoxy using CNTs resulted in a reduction in $T_{g}$ and dampening characteristics, presumably as a result of the presence of micron-sized agglomerates.
\end{abstract}

\section{Introduction}

From virtually the moment carbon nanotubes (CNTs) were discovered, it was expected that they would display superior mechanical properties as compared to carbon fibers. It has been shown that CNTs can significantly strengthen polymer matrices if the nanotubes are well dispersed, bonded, and aligned $[1,2]$. A number of reports have however also shown positive effects of the incorporation of randomly dispersed nanotubes on the crack resistance of polymer resins [38]. Gojny et al. [3], for example, reported a $43 \%$ increase in the fracture toughness of a standard epoxy resin with the addition of $0.5 \mathrm{wt} \%$ amine-functionalized double wall carbon nanotubes. Besides the (often modest) mechanical property improvements, CNTs have been especially successful in improving the electrical properties of polymers. Their combination of good intrinsic conductivity and high aspectratio makes them very interesting filler for the creation of conductive nanocomposites with low percolation thresholds [9-14]. The introduction of such CNT modified resins into already matured carbon fiber-reinforced plastics (CFRP) opens the possibility for the creation of new multifunctional multiscale materials with optimized mechanical, thermal, as well as electrical properties.

Recent interest in multiscale composite materials has often been inspired by nature which is full of interesting biocomposites with multiple hierarchical levels of reinforcement. Bone, for example, is a fascinating multiscale hierarchical composite consisting of macro-, meso-, microas well as nanofeatures, all of which are responsible for imparting unique mechanical characteristics such as high stiffness and high toughness. Man-made multiscale micronanocomposites offer a route by which multifunctionality, such as enhanced thermal stability, lower coefficient of thermal expansion, and high thermal and electrical conductivity, can be imparted to the fiber-reinforced composite through 
an addition level of hierarchy. While fiber-dominated properties of such multiscale hybrid micro-nanocomposites may benefit to some extent from the incorporation of nanoparticles, it is expected that especially resin-dominated properties will benefit the most.

The purpose of hybridization in composites is to extend the concept of tailoring properties to suit requirements and to offset the disadvantages of one component by the addition of another [15-17]. Recent research efforts in this field have focused on properties of hybrid micronanocomposites in which dispersed second phase nanoparticles are added to the epoxy matrix [18-32]. Mahrolz et al. [20] reported a significant enhancement in mechanical performance including improvements in stiffness and tensile strength, delamination resistance, and safety factors of their epoxy-based multiscale composites. Mode II fracture behavior of the laminates was examined by Karapappas et al. [18] and an increase was reported in fracture energy of the CFRP doped with $0.5 \%$ and $1 \%$ CNTs (about $45 \%$ and $75 \%$, resp.). Chen et al. $[22,23]$ prepared an epoxysilicate nanocomposite using an aerospace grade epoxy resin and carbon fibers and showed higher storage modulus as compared to neat resin properties. Gojny et al. [24] made glass fiber/CNT/epoxy composites and reported an increase in interlaminar shear strength by $20 \%$. Tsantzalis et al. $[25,26]$ doped carbon fiber reinforced epoxy laminates with carbon nanofibers (CNFs) and titanate piezoelectric (PZT) particles and reported a $100 \%$ increase in fracture energy of laminates with the addition of $1 \mathrm{wt} \%$ CNFs. Wichmann et al. [27] developed fumed silica/glass fiber/epoxy, carbon black/glass fiber/epoxy, and CNT/glass fiber/epoxy micro-nanocomposites by resin transfer moulding technique (RTM) and reported a 16\% increase in interlaminar shear strength and superior electrical properties as a result of a small addition $(0.3 \mathrm{wt} \%)$ of CNTs. Chowdhury et al. [28] investigated the effects of nanoclay on the mechanical and thermal properties of woven carbon fiber-reinforced epoxy and reported an $18 \%$ and $9 \%$ improvement in flexural strength and modulus, respectively, with the addition of $3 \mathrm{wt} \%$ nanoclay. Dean et al. reported on the synthesis and fabrication of glass fiber-reinforced composites based on vinyl ester and epoxy nanocomposites, respectively [29, 30]. Qiu et al. [32] improved electrical conductivity and mechanical properties of CFRPs by effective infiltration of CNTs using vacuum-assisted resin transfer molding technique.

Thostenson et al. [33] and Kepple et al. [34] grew CNTs on carbon fibers and embedded these fibers into an epoxy matrix and reported superior interfacial bond strength between the polymer and the CNT-modified carbon fiber. Gou et al. [35] worked on the fabrication of carbon nanofiber-modified glass fiber-reinforced polyester matrix. Vlasveld et al. [36, 37] showed a more than $40 \%$ increase in flexural and compressive strength at elevated temperatures with the incorporation of $10 \mathrm{wt} \%$ nanoclay in continuous fiber-reinforced thermoplastics. Additional interesting properties of nanocomposite resins for advanced composites reported in literature are a reduced creep rate [37] and coefficient of thermal expansion [38], improved

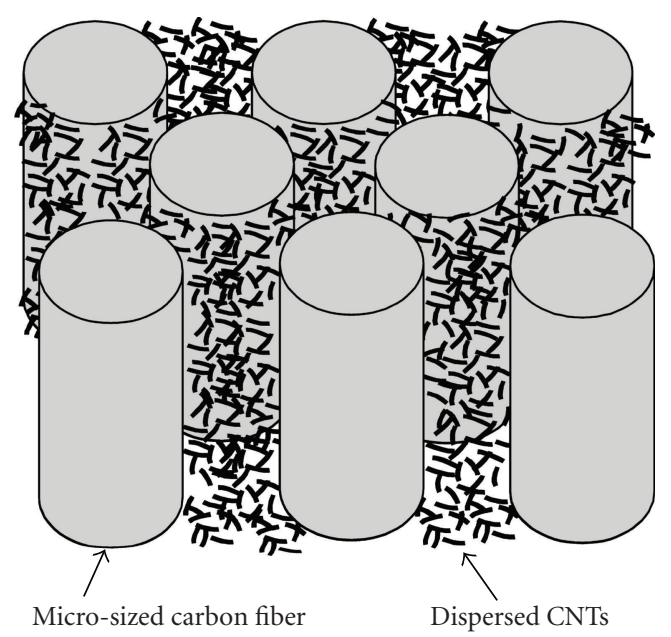

FIGURE 1: Multiscale hybrid micro-nanocomposite based on CNTs and carbon fiber. (adopted from [36]).

barrier properties for gasses and vapors [39, 40], and reduced flammability [37, 41, 42]. Micron-sized carbon fibers coated with aligned CNTs and their derivatives provide an effective means to connect nanoscale entities to the macroscopic world and were shown to possess interesting electrochemical properties attractive for a wide range of potential applications, including methanol direct fuel cells and highly sensitive chemical and biological sensors [43]. Frankland et al. [44] modeled multiscale hybrid micro-nanocomposites based on CNT/carbon fiber/epoxy and indicated that the presence of nanotubes near the surface of carbon fibers can have a small, but positive, effect on the properties of the lamina.

The use of the nanotube-modified epoxies as a matrix system for carbon fiber-reinforced composites has not been fully studied, which is the aim of this study. It is not the aim of this study to replace any continuous carbon fiber with CNTs. However, dispersing them in small amounts in the polymer resin can potentially enhance matrix-dominated properties of these carbon fiber composites (Figure 1). In this work, we prepared multiscale hybrid micro-nanocomposites, based on amino-functionalized double wall carbon nanotubes (DWCNT- $\mathrm{NH}_{2}$ ), carbon fiber fabrics, and epoxy matrix.

\section{Experimental Details}

2.1. Materials. The epoxy matrix used in this study consists of a CYCOM 823 RTM liquid epoxy resin with an aromatic anhydride hardener, supplied by Cytec Engineering Materials Ltd., UK. This epoxy system is a standard resin for the aerospace industry and infusion processes [45]. Plain weave carbon fiber fabric $\left(\mathrm{P} 1726,0 / 90^{\circ}\right)$, with an areal density of $0.445 \mathrm{~kg} / \mathrm{m}^{2}$, was also obtained from Cytec. Cadek et al. [46] showed that DWCNTs-polymer composites, as compared to other CNTs, give potentially the best balance of properties in terms of dispersibility and mechanical properties for use as reinforcement of polymers. Amino-functionalized CNTs 


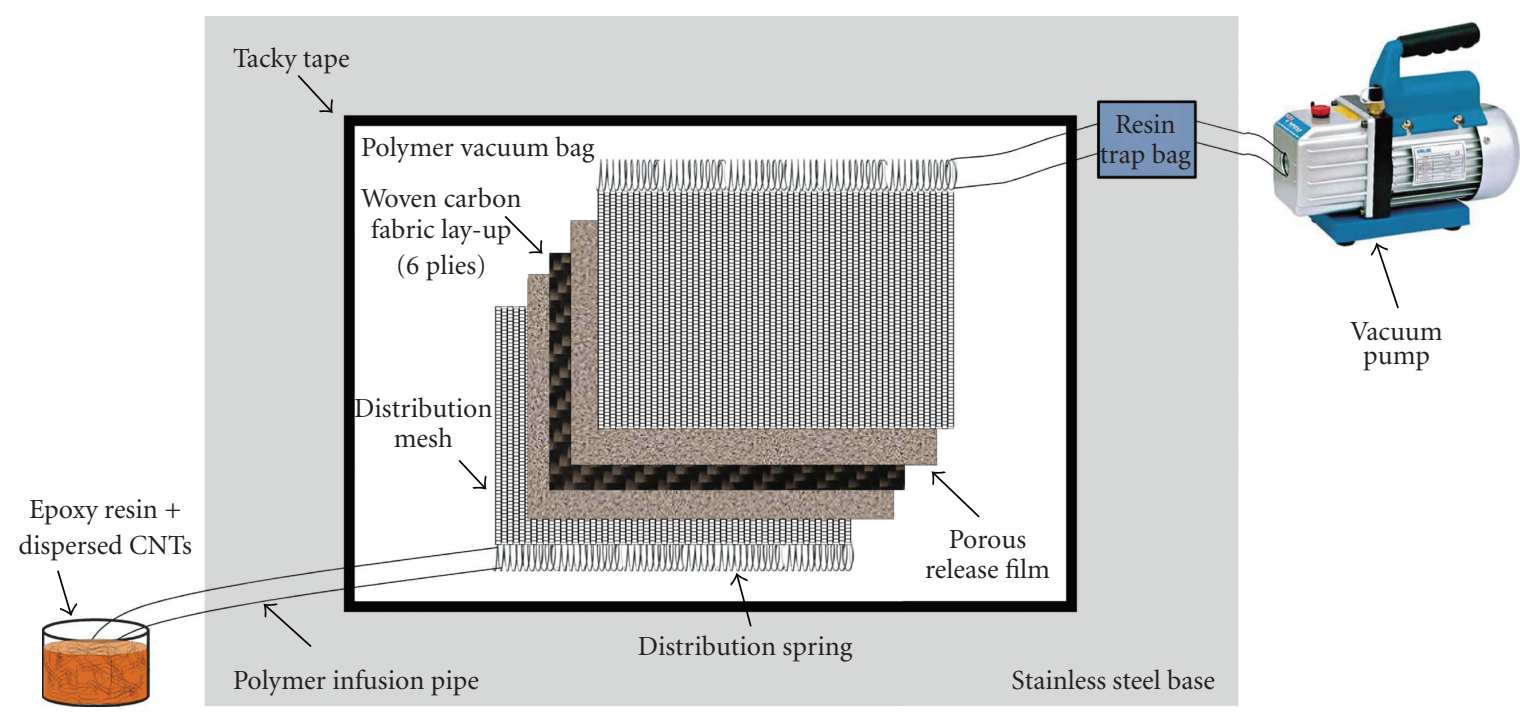

FIgURe 2: Vacuum infusion lay-up sequence.

lead to a more homogeneous distribution in the matrix and a reduced risk for agglomerates, as compared to pristine CNTs $[4,5]$. DWCNT-NH ${ }_{2}$ (Nanocycl 2152) was supplied by Nanocyl S.A., Belgium. As per supplier, these CNTs were synthesized by CVD method, having diameters of around $4.7 \mathrm{~nm}$, lengths up to several microns, a carbon purity of more than $90 \%$, and a functionalization of less than $0.5 \%$.

2.2. Dispersion Procedure. Three compositions (0.025, 0.05, and $0.1 \mathrm{wt} \%$ ) of DWCNT- $\mathrm{NH}_{2}$ were dispersed in the epoxy matrix using a high-power bath ultrasonication (Decon Ultrasonics Ltd, FS Minor, 75 Watts) for five hours. As per authors' previous work [47], this method is highly effective for lower concentrations of CNTs and results in a good level of dispersion. Anhydride hardener (20 wt\%) was added after dispersing CNTs in epoxy. The mixtures were extensively hand-mixed for 5 minutes. After degassing (at $50^{\circ} \mathrm{C} / 30 \mathrm{~mm} \mathrm{Hg}$ ) the suspension for 30 minutes in a vacuum oven, one batch of materials was used to make DWCNT-NH $\mathrm{N}_{2}$ /epoxy nanocomposites by an open mould casting method, while a second batch was used for the manufacturing of the hybrid micro-nanocomposites by vacuum infusion technique.

2.3. Open Mould Casting. The homogenized suspensions were slowly poured between two mirror-polished stainless steel plates at an angle $\left(\sim 30^{\circ}\right)$ in a vertical position to prevent entrapment of air bubbles during casting. Demoulding spray (Frekote 44, Hysol, The Dexter Corp.) was applied to the plates before casting for easy separation. The resin was cured at $125^{\circ} \mathrm{C}$ (heating rate $=1{ }^{\circ} \mathrm{C} / \mathrm{min}$ ) for an hour and cooled slowly in an oven to avoid thermally induced matrix cracking. The thickness of the epoxy nanocomposite plates was $3 \pm 0.25 \mathrm{~mm}$. No voids and shrinkage marks were observed by the naked eye. The same procedure was employed to make neat epoxy plates.
2.4. Vacuum Infusion. The dispersed mixtures were slowly infused into a vacuum bag containing six plies of woven carbon fabric with a $\left(0 / 90^{\circ}\right)$ lay-up under a negative pressure (Figure 2). The authors would like to emphasize that even the small amounts of DWCNT- $\mathrm{NH}_{2}$ employed in this study drastically increased the viscosity of the matrix. To reduce the viscosity and promote fluidity, the colloidal suspension and vacuum infusion stainless steel base was heated to $50^{\circ} \mathrm{C}$. The infused lay-up was cured at $125^{\circ} \mathrm{C}$ (heating rate $=1^{\circ} \mathrm{C} / \mathrm{min}$ ) for an hour and slowly cooled in a closed oven to avoid matrix cracking. The thickness of the laminates was $3 \pm$ $0.30 \mathrm{~mm}$. By matrix digestion test [48], the fiber volume fraction and void content was estimated to be $55 \%$ and $0.5 \%$, respectively. More details of this process are described elsewhere [28]. The same procedure was followed for making neat carbon fiber-reinforced epoxy laminates without CNTs. A list of specimens prepared is given in Table 1. For the mode I interlaminar fracture toughness testing, the same lay-up and resin infusion procedures were carried out. However, an insert film, made of $12 \mu \mathrm{m}$ thick PTFE film, was placed in the mid-plane of the lay-up to create a crack opening.

2.5. Mechanical Characterization. Flexural strength was measured in a three-point bending test using an Instron 6025 screw-driven universal tensile testing machine at a crosshead speed of $5 \mathrm{~mm} / \mathrm{min}$ at room temperature. At least five specimens were tested for each composition. Double cantilever beam (DCB) specimens were prepared for mode I fracture toughness tests according to ASTM D5528-01. The composite specimens were cut to size $(120 \mathrm{~mm} \times 20 \mathrm{~mm})$ and a composite material made of glass fiber and epoxy (commonly used for end-tabs) was cut $(120 \mathrm{~mm} \times 20 \mathrm{~mm}$ ) and bonded to both sides of the specimens to increase the flexural regidity. Piano hinges were bonded to the ends of the specimens, and the distance between the loading points to the end of the insert film (beginning of the crack) was $50 \mathrm{~mm}$. The sides of the specimens were spray painted with 
TABLE 1: Samples prepared for this study.

\begin{tabular}{|c|c|c|c|c|}
\hline Sample description & Method of preparation & Sample ID & Fiber volume fraction (\%) & Void Content $(\%)$ \\
\hline Neat epoxy & Open mould casting & A & - & Negligible \\
\hline 0.025 wt $\%$ DWCNT-NH ${ }_{2}+$ epoxy & Open mould casting & $\mathrm{B}$ & - & Negligible \\
\hline $0.05 \mathrm{wt} \%$ DWCNT-NH$H_{2}+$ epoxy & Open mould casting & $\mathrm{C}$ & - & Negligible \\
\hline 0.1 wt $\%$ DWCNT-NH ${ }_{2}+$ epoxy & Open mould casting & $\mathrm{D}$ & - & Negligible \\
\hline CF + epoxy & Vacuum infusion & $\mathrm{E}$ & 56.5 & 0.50 \\
\hline 0.025 wt $\%$ DWCNT-NH ${ }_{2}+\mathrm{CF}+$ epoxy & Vacuum infusion & $\mathrm{F}$ & 55 & 0.67 \\
\hline $0.05 \mathrm{wt} \%$ DWCNT-NH$H_{2}+\mathrm{CF}+$ epoxy & Vacuum infusion & G & 57 & 0.80 \\
\hline
\end{tabular}

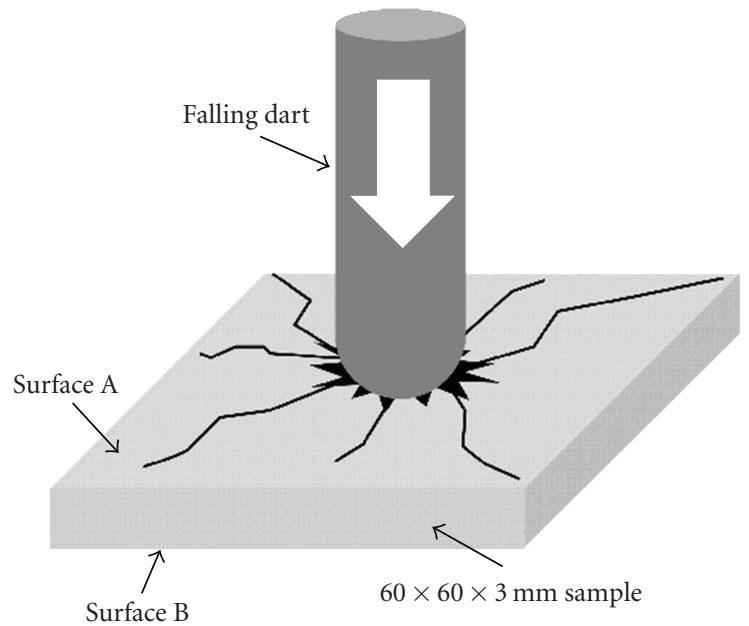

FIGURE 3: Schematics of falling dart impact testing.

a white paint primer, and marking was drawn on the primer for every $\mathrm{mm}$. The sample was loaded in tensile mode in a Hounsfield universal testing machine, at $1 \mathrm{~mm} / \mathrm{min}$. Crack growth was observed using a digital microscope and the measurements of load and displacement at corresponding crack length were recorded. The $\mathrm{G}_{\mathrm{IC}}$ values in this study were calculated using the modified beam theory (MBT) using (1):

$$
\mathrm{G}_{\mathrm{IC}}=\frac{3 P \delta}{2 b(a+|\Delta|)},
$$

where $P$ is the load, $\delta$ is the load point displacement, $b$ is specimen width, $a$ is the delamination length, and $\Delta$ is determined experimentally by generating a least square plot of the cube root of compliance, $\mathrm{C}^{1 / 3}$, as a function of delamination length.

Dynamic modulus and viscoelastic response was studied in a DMA Q800 (TA Instruments ltd., UK) in bending mode at a frequency of $1 \mathrm{~Hz}$. Heating occurred at a rate of $5^{\circ} \mathrm{C} / \mathrm{min}$ and in a temperature range between 30 and $200^{\circ} \mathrm{C}$. Flexural properties were measured according to ASTM D 790-03 $($ sample size $=68 \times 12.7 \times 3 \mathrm{~mm}$, span-to-depth ratio $=16)$. Similar size samples were used in DMA.

Energy absorption during impact was measured on flat plates $($ sample size $=60 \times 60 \times 3 \mathrm{~mm})$ using a Ceast instrumented dart impact tester (Dart Vis, diameter = $18 \mathrm{~mm}$ ) fitted with a data acquisition system (Figure 3 ). The laminates were clamped between two plates. At least five samples were tested for each composition and were impacted at a fixed initial impact energy level of 6 joules. Ultrasonic C-scan was performed using a jet probe inspection system (Midas-NDT) to measure the damaged area in laminates.

2.6. Field Emission Scanning Electron Microscopy. Small samples were cut from fractured specimens. All samples were gold coated and then transferred to an FE-SEM (FEI, Inspect $\mathrm{F}, 10 \mathrm{kV}$ ) for examination. Gold coating was done to visualize agglomerates rather than individual CNT.

\section{Results and Discussion}

3.1. SEM Characterization. Using SEM analysis, the interply resin (between 3rd and 4th ply) of the cured laminate was studied to evaluate the level of impregnation of the nanotube modified resin within the carbon fiber plies as well as in between the plies. Figure 4 shows the interply region in the centre of the woven fabric laminate (between 3rd and 4th plies). No clear filtering effect of the carbon fabric on the DWCNT-NH$H_{2}$ for samples $F$ and $G$ was observed, as was reported in earlier studies [27]. However, for sample $\mathrm{H}$, which contains $0.1 \mathrm{wt} \%$ DWCNT- $\mathrm{NH}_{2}$, there was a clear difference in the clearness of the resin coming out of the suction line, indicating lower nanotube content due to filtering of larger agglomerates present in this resin system by the carbon fabric. It should be noted that due to the large difference in scale, it is not possible to directly observe both DWCNTs- $\mathrm{NH}_{2}$ and carbon fibers in the same image (see Figures $4(\mathrm{a})$ and 4(b)). Agglomerates of DWCNT-NH$H_{2}$ are visible in Figures 4(b) and 4(c) for sample F. The lower viscosity may lead to better wetting of the carbon fibers and dispersion of the DWCNT- $\mathrm{NH}_{2}$ but a nonuniform distribution of CNT aggregates is observed in Figure $4 \mathrm{~b}$. The nonuniform dispersion of DWCNT- $\mathrm{NH}_{2}$ (Figures 4(a), 4(b), and 4(c)) in between carbon fiber layers should be due to the aggregate nature of CNTs because of their high specific surface area and strong interaction forces between them. Key failure mechanisms in continuous fiber reinforced composites like fiber fracture, fiber pull-out, fiber/matrix debonding, crack bridging (Figure 4(d)), and matrix cracking have also been observed in CNT-modified polymer composites as demonstrated by Thostenson and 


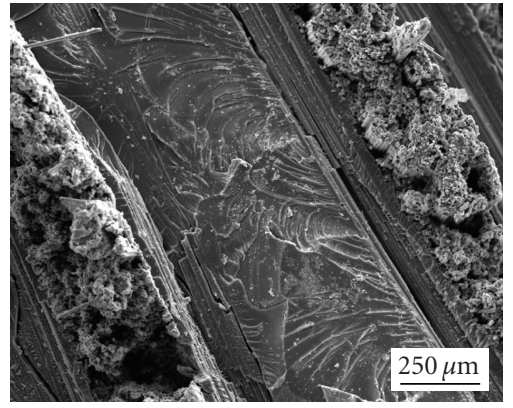

(a)

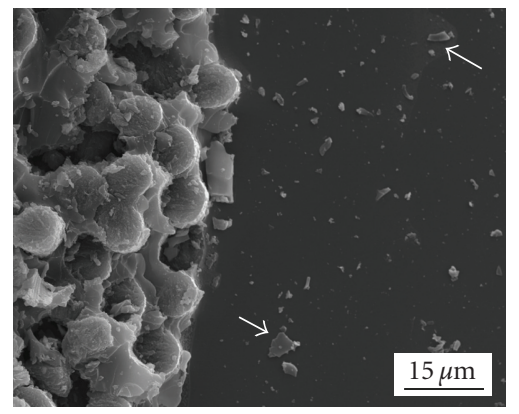

(c)

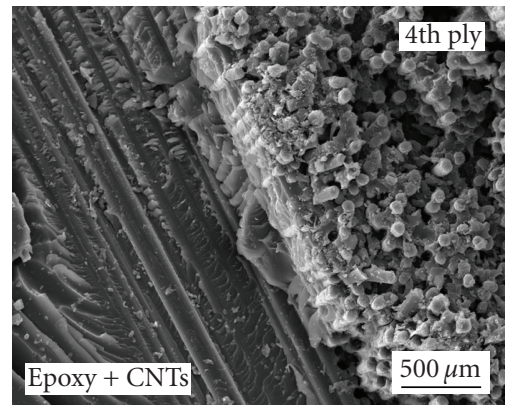

(b)

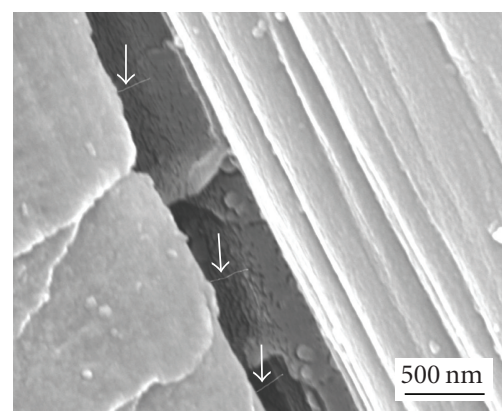

(d)

FIGURE 4: FE-SEM images of hybrid (0.025 wt\% DWCNT-NH $\mathrm{NH}_{2}$ micro-nanocomposites: (a), (b) middle of cured laminate (between 3rd and 4th plies), (c) agglomerates of DWCNT- $\mathrm{NH}_{2}$ (pointed), and (d) individual DWCNT-NH $\mathrm{N}_{2}$ bridging epoxy matrix (pointed).

Chou $[49,50]$ and the same is expected for these hybrid micro-nanocomposites.

\subsection{Flexural Testing. So far nanotube-filled polymers have} not had many industrial successes in which they showed a mechanical property advantage over traditional carbon fibers [51], even though the potential reinforcing properties, notably strength, of CNTs are superior to those of carbon fibers [52]. The low loadings of CNTs often employed in epoxy resins imply less inhomogenities but also less positive perturbations of mechanical properties [53]. Previous attempts to combine nanocomposites with micron-size fibers often resulted in a strong decrease in strength, presumably caused by poor adhesion [37]. In our case, adding CNTs to CFRP imparted a small increase in flexural strength (Figure 5(a)) of around 5\% for sample F, indicating a good bonding between the CNT-modified epoxy resin and the carbon fibers. Nanotube modification of the pure epoxy resin showed an increase in flexural strength of nearly 50\% for sample C, but this is still significantly below the theoretically predicted values [54]. Flexural strength of the CNT/epoxy nanocomposites increased up to a loading of $0.05 \mathrm{wt} \%$ of DWCNT- $\mathrm{NH}_{2}$ (sample C) and then decreased, presumably due to agglomeration at higher nanotube concentrations. For hybrid micro-nanocomposites flexural strength only increased up to $0.025 \mathrm{wt} \%$ of DWCNT- $\mathrm{NH}_{2}$ (sample F). As compared to sample A, a very small improvement in flexural stiffness (Figure 5(b)) for samples B (10\%), C (11\%), and D $(8 \%)$ was observed. However, the introduction of DWCNT$\mathrm{NH}_{2}$ in CFRP resulted in a near 35\% improvement in flexural modulus for sample G. Flexural modulus increased up to $0.05 \mathrm{wt} \%$ of DWCNT-NH${ }_{2}$ (sample G) and then decreased.

3.3. Impact Testing. Falling-weight impact testing has potential for evaluating the damage tolerance of laminated composite materials. This type of testing gives significant information about failure mechanisms and behavior of materials under low velocity impact [17, 55]. Postprocessing of the measured impact parameters, force, time, and impact velocity results in the complete energy history and the energy absorbed during impact by the composite laminate. Upon impact the total impact energy can be divided into two parts. The first is the elastically stored energy in the composite plate, which is released after maximum deflection by rebouncing of the laminate. This rebouncing energy is successfully transferred back to the impactor. The second is, the energy absorbed in the composite laminate available for damage that consequently controls the extent of damage and residual strength $[16,17$, $55]$.

To study the impact damage tolerance of the micronanocomposites, here, the authors only report the "absorbed energy" of the composite laminates. It should be noted that the neat resin-based samples A, B, C, and D cannot be compared with the CFRP-based samples E, F, G, and $\mathrm{H}$. The first four samples were too brittle and shattered upon (full-penetrating) impact, whereas the latter four containing carbon fiber did not penetrate. The energy absorbed, calculated by the area under the force-displacement curve, is presented in Figure 5(c). CNTs improved the impact strength 


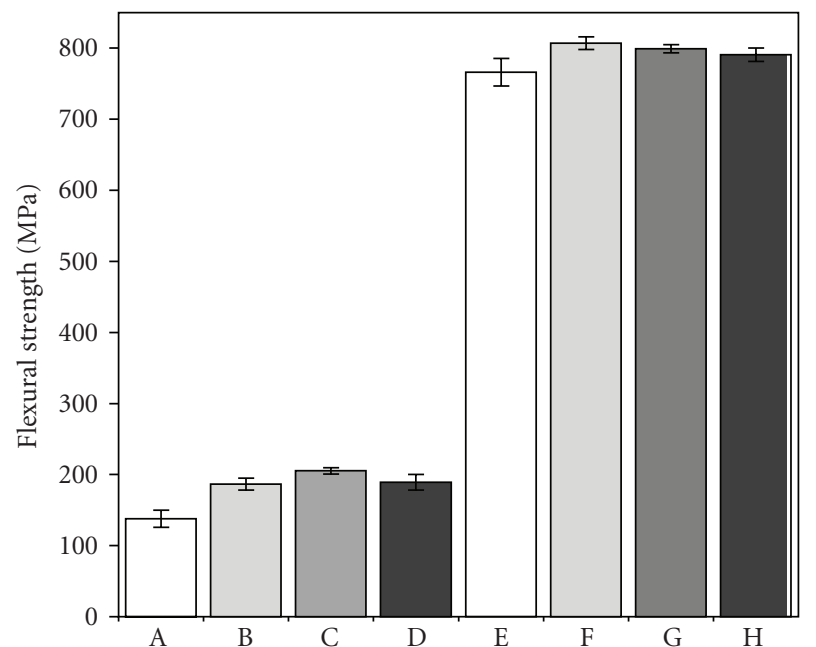

(a)

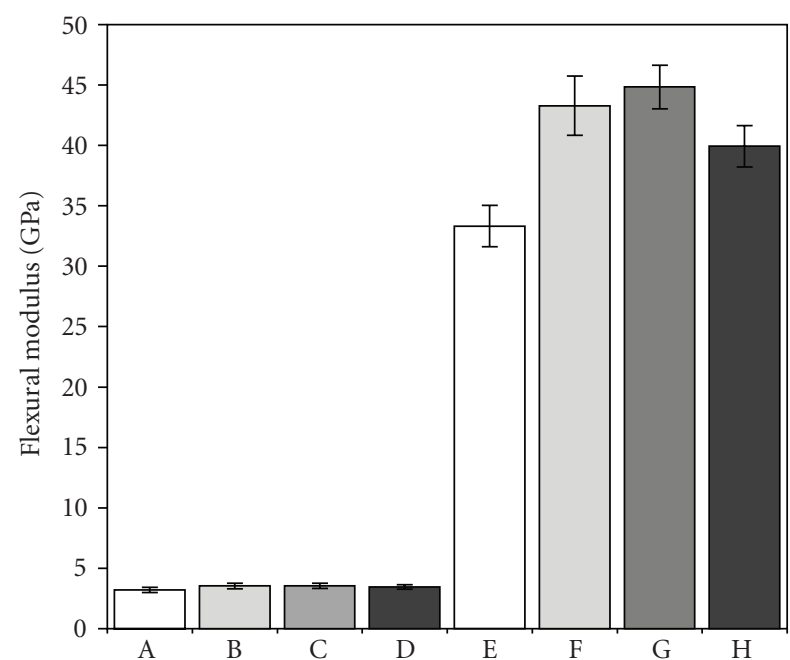

(b)

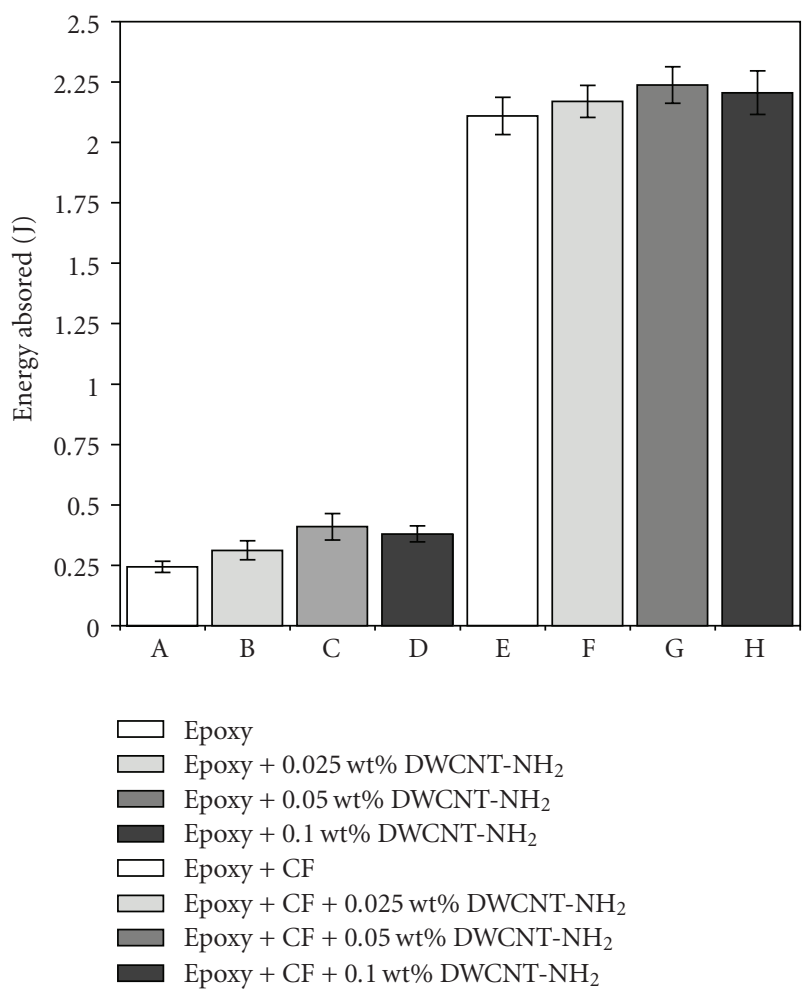

(c)

FIgURE 5: Mechanical characterizations (three-point bending test and drop-weight impact test): (a) flexural strength, (b) flexural modulus, and (c) energy absorbed (area under the curve of force versus displacement).

by up to $30 \%$ (sample C) for the nanotube-modified epoxy resin. In the case of hybrid micro-nanocomposites, carbon fibers were expected to absorb most of the energy during impact because of their large volume. After hybridization, slightly more energy was absorbed by the hybrid micronanocomposites. However, no significant effect on damage area was observed in the ultrasonic C-scans (Figure 6). Hybridized (0.1 wt \% CNTs) and nonhybridized CFRP laminates both showed similar damage areas $\left(\sim 254 \mathrm{~mm}^{2}\right)$ on the impacted surface (Figure 6). At the initial impact energies of 6 Joules, no damage was detected at the nonimpacted surfaces (surface B, Figure 3) of the laminates. Results in Figure 5(c) show a negligible enhancement in the energy absorbed by samples $\mathrm{F}$ (3\% improvement) and $\mathrm{G}(6 \%$ improvement) as a result of the presence of DWCNT-NH 2 . This small increase was not very exciting given the large 


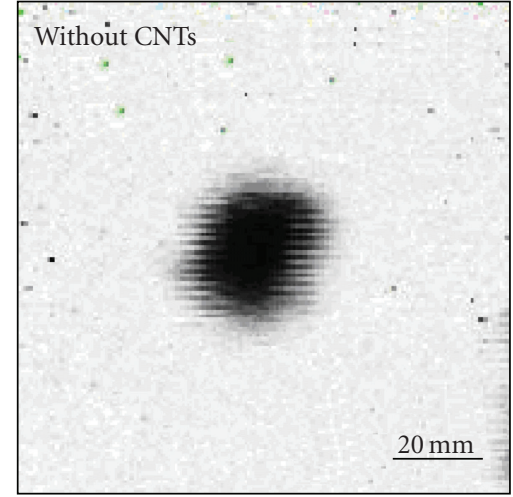

(a)

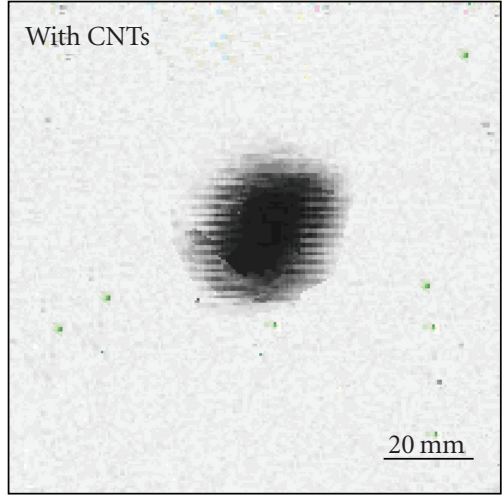

(b)

FIGURE 6: C-scan images of nonhybridized CFRP and hybridized ( $0.1 \mathrm{wt} \% \mathrm{CNTs}$ ) micro-nanocomposite.

increase in surface area offered by the CNTs. Regarding the enormous surface area of nanofillers, only small volume fractions of CNTs are needed to modify a large volume of the matrix, resulting in a high interphase fraction [27]. Energy absorbed by the hybrid micro-nanocomposites increased only up to loadings of $0.05 \mathrm{wt} \%$ DWCNT-NH 2 (sample G) and then decreased for sample $\mathrm{H}$. A similar trend was also observed for epoxy nanocomposites in which the maximum energy was absorbed by sample C ( $0.33 \mathrm{~J}, 30 \%$ enhancement as compared to neat epoxy). However, compared to standard rubber or thermoplastic toughened epoxy systems these enhancements in impact toughness of CFRP through the introduction of CNTs are not all that significant. Significantly higher improvements in toughness can be achieved using more traditional methods such as polymer blends [56] or hybridization with other more ductile fibers $[16,17,57$, 58].

3.4. Mode I Fracture Toughness Analysis. The load-displacement curve (Figure 7) of the CFRP laminate without CNTs shows a stick-slip failure mode which is common for epoxy laminates. Stick-slip fracture follows a crack propagation and crack arrest behavior which indicates unstable crack growth. In neat CFRP composites the crack propagated gradually and only a small drop in load was recorded (Figure 7). The laminate with $0.1 \mathrm{wt} \% \mathrm{CNTs}$ also shows a stick-slip fracture mode. However, as there are less drop steps in the load-displacement curve for the hybrid micronanocomposite, fracture was fast and more catastrophic, as compared to cracking in the neat CFRP composite. Consequently, load decreases significantly during propagation of the crack for hybrid micro-nanocomposites. Average $G_{I C}$ values for nonhybridized CFRP microcomposites and hybridized micro-nanocomposites are $0.38 \mathrm{~kJ} / \mathrm{m}^{2}$ and $0.31 \mathrm{~kJ} / \mathrm{m}^{2}$, respectively. Hence, the mode I interlaminar fracture toughness decreased $(\sim 23 \%)$ with the introduction of the CNT. FE-SEM images of fractured surfaces are shown in Figure 8. Both fracture surfaces show hackle formation as the predominant failure mode for both matrices.

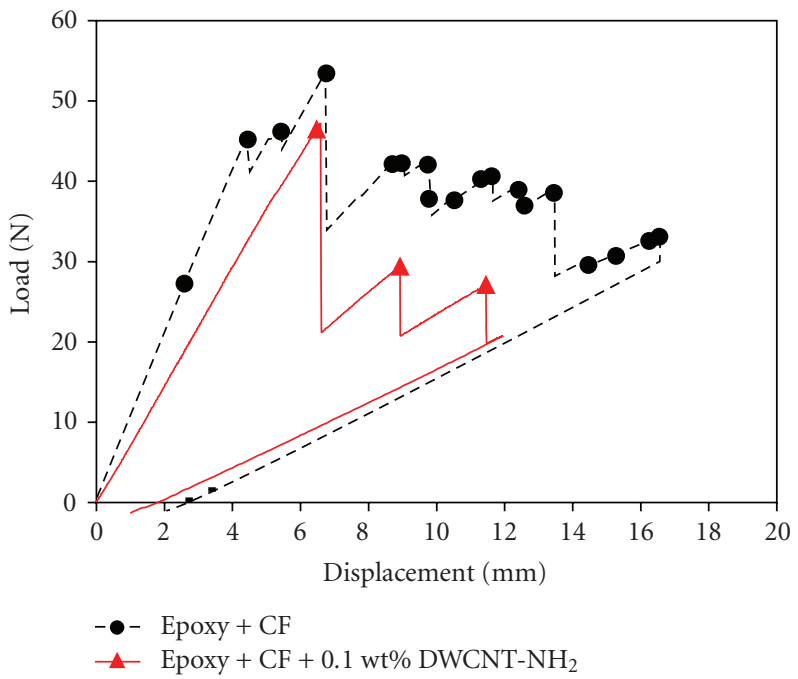

Figure 7: Mode I interlaminar fracture toughness analysis of nonhybridized CFRP and hybridized (0.1 wt $\%$ DWCNT- $\left.\mathrm{NH}_{2}\right)$ micro-nanocomposite. Data points represent stick-slip fracture mode.

3.5. Dynamic Mechanical Analysis. Dynamic mechanical analysis (DMA) is a powerful technique for studying the viscoelastic behavior of polymer-based materials. It is also the preferred method of measuring the glass-transition temperature $\left(T_{g}\right)$ of polymeric materials. Experiments involve the application of an oscillatory stress to the sample while monitoring the resulting strain which consists of both inphase and out-of phase components. The strain can then be used to calculate the in-phase response, or storage modulus $\left(G^{\prime}\right)$, and the out-of-phase response, or loss modulus $\left(G^{\prime \prime}\right)$. The ratio of $G^{\prime} / G^{\prime \prime}$ is known as the $\tan \delta$, which is a parameter for the damping characteristics of materials. The $T_{g}$ is determined by the corresponding peak of the loss modulus curve [51] or $\tan \delta$.

As expected from the three-point bending results, CNTs improved the storage modulus of the nanocomposites and the hybrid micro-nanocomposites, as evidenced from 


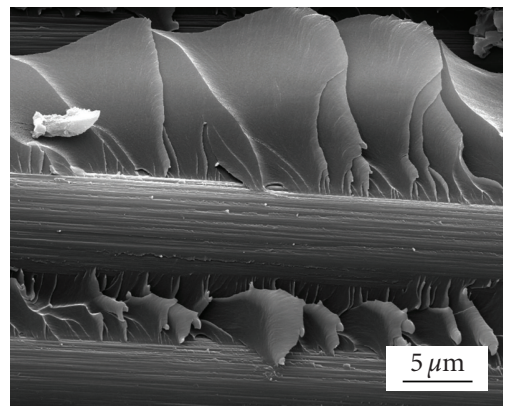

(a)

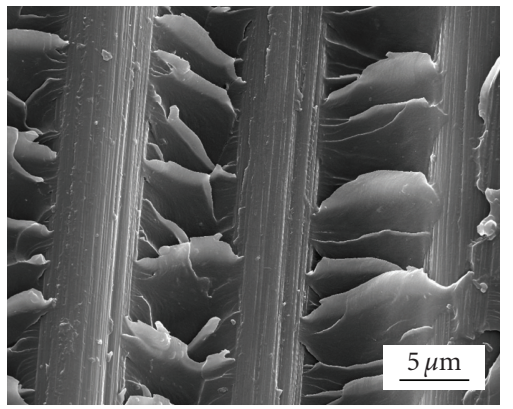

(b)

FIGURE 8: FE-SEM images of mode I fractured surface: (a) nonhybridized CFRP, and (b) hybrid micro-nanocomposite (0.1 wt\% DWCNT$\left.\mathrm{NH}_{2}\right)$.

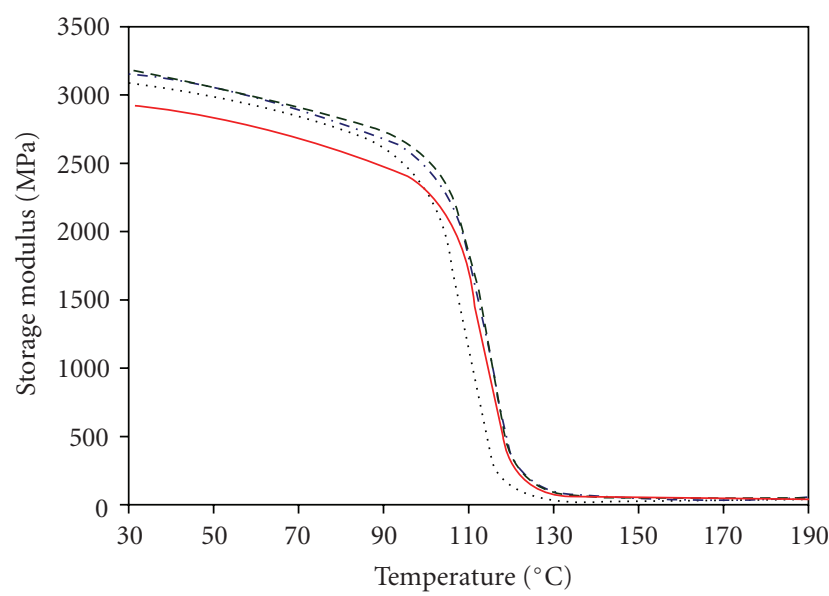

(a)

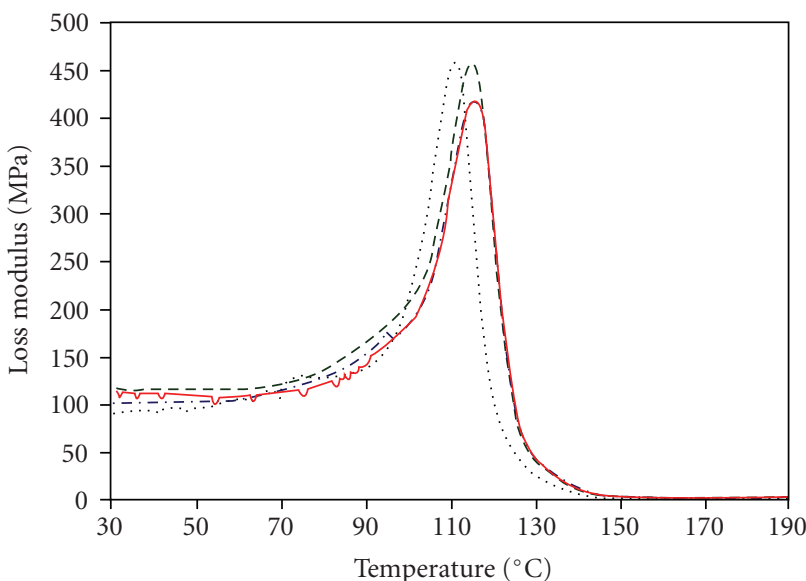

…. Epoxy

- - - Epoxy + $0.025 \mathrm{wt} \%$ DWCNT-NH $\mathrm{N}_{2}$

-. - Epoxy + $0.05 \mathrm{wt} \%$ DWCNT-NH

— Epoxy $+0.1 \mathrm{wt} \%$ DWCNT-NH ${ }_{2}$

(c)

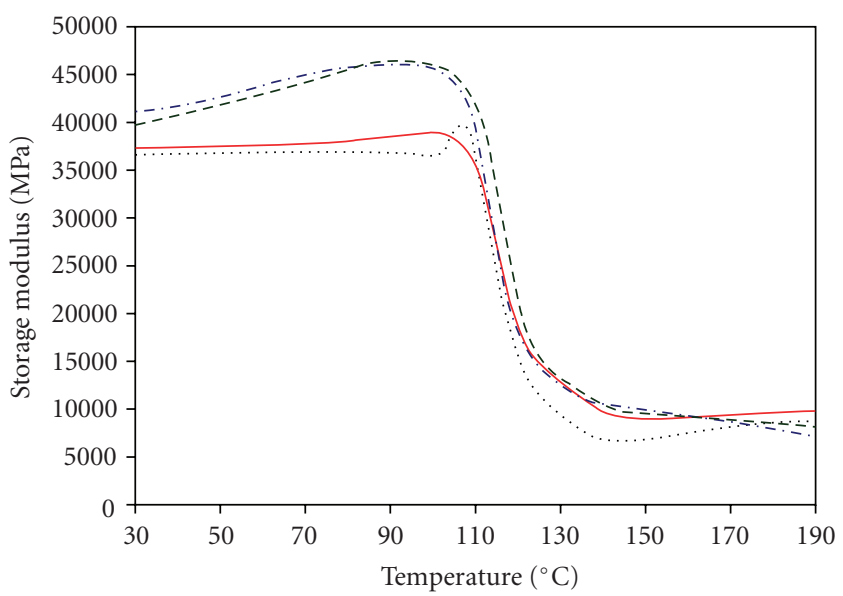

(b)

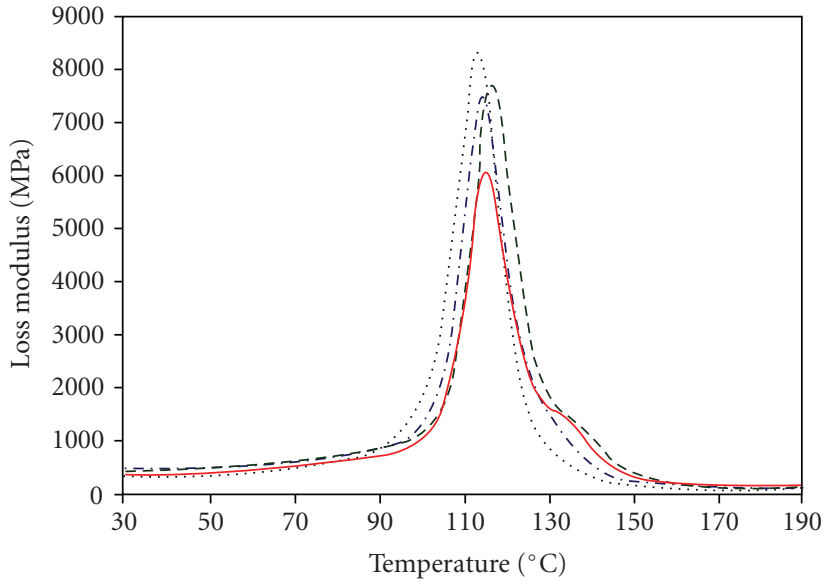

…. Epoxy $+\mathrm{CF}$

- - - Epoxy + CF + 0.025 wt $\%$ DWCNT-NH ${ }_{2}$

- . - Epoxy + CF + $0.05 w t \%$ DWCNT-NH

- Epoxy $+\mathrm{CF}+0.1 \mathrm{wt} \%$ DWCNT-NH ${ }_{2}$

(d)

FIGURE 9: Dynamic mechanical analysis: (a) storage modulus for neat epoxy and nanocomposites, (b) storage modulus for CFRP and hybrid micro-nanocomposites, (c) loss modulus for neat epoxy and nanocomposites, and (d) loss modulus for CFRP and hybrid micronanocomposites. 
TABLE 2: Effect of CNTs on glass transition temperature and tan-delta for nanocomposites and hybrid micro/nanocomposites.

\begin{tabular}{|c|c|c|c|}
\hline Sample description & Sample ID & Glass transition temperature $\left({ }^{\circ} \mathrm{C}\right)$ & Tan-delta* \\
\hline Neat epoxy & A & $116 \pm 3$ & $34 \pm 2$ \\
\hline $0.025 \mathrm{wt} \%$ DWCNT-NH $\mathrm{N}_{2}+$ epoxy & B & $122 \pm 4$ & $27 \pm 3$ \\
\hline $0.05 \mathrm{wt} \%$ DWCNT-NH ${ }_{2}+$ epoxy & $\mathrm{C}$ & $122 \pm 5$ & $31 \pm 4$ \\
\hline $0.1 \mathrm{wt} \%$ DWCNT-NH ${ }_{2}+$ epoxy & $\mathrm{D}$ & $122 \pm 3$ & $26 \pm 4$ \\
\hline $\mathrm{CF}+$ epoxy & $\mathrm{E}$ & $118 \pm 5$ & $108 \pm 4$ \\
\hline $0.025 \mathrm{wt} \%$ DWCNT-NH ${ }_{2}+\mathrm{CF}+$ epoxy & $\mathrm{F}$ & $118 \pm 3$ & $89 \pm 3$ \\
\hline $0.05 \mathrm{wt} \%$ DWCNT-NH $2+\mathrm{CF}+$ epoxy & G & $118 \pm 6$ & $84 \pm 4$ \\
\hline $0.1 \mathrm{wt} \%$ DWCNT-NH$H_{2}+\mathrm{CF}+$ epoxy & $\mathrm{H}$ & $118 \pm 4$ & $100 \pm 3$ \\
\hline
\end{tabular}

*at room temperature.

Figures 9(a) and 9(b). It can be seen in Figure 9(a) that sample D (0.1 wt\% CNT/epoxy) possessed a lower storage modulus as compared to neat epoxy and other nanocomposites (having lower concentrations) over the temperature range $\left(30-130^{\circ} \mathrm{C}\right)$. This is an indication that agglomerates in sample D may act as flaws, lowering the storage modulus. Above $130^{\circ} \mathrm{C}$ neat epoxy and all the epoxy nanocomposites possessed the same storage modulus, indicating that the presence of nano-reinforcement was not significant above $T_{g}$. A similar trend was observed for the micro-nanocomposites as shown in Figure 9(b). Sample H (0.1 wt\% CNT/CF/epoxy) possessed an inferior storage modulus as compared to other lower compositions of hybrid micro-nanocomposites over the temperature range 30 to $115^{\circ} \mathrm{C}$. At high temperatures, the loss modulus of the nanocomposites and the hybrid micronanocomposites decreased with increasing CNT content, shifting the $T_{g}$ peak downward (Figures 9(c) and 9(d)). Higher concentrations possessed lower-energy dissipation ability as well. This effect is very clear at higher temperature (above $90^{\circ} \mathrm{C}$ ). Hence, it can be concluded that dampening characteristics $(\tan \delta$ ) of nanocomposites and hybrid micro-nanocomposites start to improve above 90 $100^{\circ} \mathrm{C}$, because of increased energy dissipation ability of the matrix.

Based on the $\tan \delta$ peak, the $T_{g}$ for all samples are given in Table 2. At least five samples were tested for each condition. According to Table 2, CNTs slightly enhanced the $T_{g}$ of epoxy nanocomposites up to $6^{\circ} \mathrm{C}$ (sample $\mathrm{C}, T_{g}=122^{\circ} \mathrm{C}$ ). Instead of having a positive effect on $T_{g}$, hybridization resulted in a reduction in $T_{g}$, possibly due to a more nonuniform distribution of CNT's in the CFRP laminates as a result of filtering effects by the carbon fabrics [59]. These results are consistent with the work performed by Lee et al. [59]. It is interesting to note that micro-nanocomposites and epoxy nanocomposites showed inferior dampening properties (at room temperature) as compared to CFRP and neat epoxy, respectively. Here it can be concluded that hybridization with CNTs results in a significant reduction (22\% in case of sample G) in dampening properties of these composites at room temperature. More work needs to be done to explain this reduction in properties and the nonuniform behavior in Table 2. On the other hand, lower values for loss modulus at higher temperatures (near
$T_{g}, 110-130^{\circ} \mathrm{C}$ ) in Figures 9(c) and 9(d) suggest higher dampening characteristics of hybrid micro-nanocomposites and nanocomposites containing higher CNT concentrations.

Most of the mechanical features of hybrid micronanocomposite started to decrease above $0.05 \mathrm{wt} \% \mathrm{CNT}$, mainly because of three reasons: (i) filtering of CNTs by the carbon fabric, leading to reduced dispersion and inhomogeneous CNT dispersions throughout the laminate; (ii) higher CNT contents in epoxy reducing the wetting and bonding between carbon fibers and the nanotube modified resin [60]; and (iii) agglomeration, which has a significant effect on the strength, stiffness, and especially toughness of the CNT-modified epoxy $[59,61]$. The presence of large agglomerates decreases the effective surface area of CNTs or, in other words, reduces the efficiency of the nanoreinforcement. For pure nanocomposites (samples B, C, and D) the latter reason is more appropriate, explaining the drop in mechanical properties with the addition of 0.05 wt $\%$ CNTs. CNTs need to be separated from the bundles and dispersed uniformly in a polymer matrix to maximize their interaction with the matrix [50]. In a CNT/polymer composite, aggregation of CNTs may become a defect that causes the mechanical properties of the resin and hence the composite to deteriorate. Therefore, the primary problem in fabricating a nanocomposite is to ensure a homogeneous dispersion of CNTs in the polymer matrix. So far, only ultrasonic, three-roll milling and high-speed mechanical stirring have been verified to be effective methods for the dispersion of CNT in epoxy resin [62]. But from this study, it appeared that bath ultrasonication is a good way to disperse lower concentrations of CNT in epoxy. Better homogenizing techniques should be employed for dispersing higher contents of CNTs in epoxy. The results of Allaoui et al. [63] suggest that it would not be helpful to use high CNTs concentrations to improve the mechanical properties of composites if they are in random distribution. The upper limit, for the addition of CNTs, is governed by the distribution and topology (aspect ratio) of the CNTs. Similar to short fiber composites, the orientation of the nanofibers plays an important role, and the higher the degree of alignment of CNTs, the higher their reinforcing efficiency [64]. 


\section{Conclusion}

Multiscale hybrid micro-nanocomposites offer a route by which multifunctionality can be introduced in fiberreinforced composites. DWCNT- $\mathrm{NH}_{2}$ /carbon fiber/epoxy micro-nanocomposites were prepared and their mechanical properties were compared with their respective pure microand nanocomposites. Apart from flexural modulus, fracture toughness, $T_{g}$, and $\tan \delta$, CNTs imparted a rather minor enhancement in mechanical properties of woven fabricbased CFRP. The addition of small amounts of CNTs $(0.025$, 0.05 , and $0.1 \mathrm{wt} \%$ ) to epoxy resins for the fabrication of multiscale carbon fiber composites resulted in a maximum enhancement in flexural modulus by $35 \%$, a $5 \%$ improvement in flexural strength, a $6 \%$ improvement in absorbed impact energy, and a $23 \%$ decrease in the mode I interlaminar toughness. Hybridization of carbon fiberreinforced epoxy using CNTs also resulted in a reduction in $T_{g}$ and dampening characteristics, owing to the presence of micron-sized agglomerates. However, even without these aggregates, it was concluded that DWCNT- $\mathrm{NH}_{2}$ achieved only a limiting toughening effects in the CFRP. Especially compared to standard rubber or thermoplastic toughened epoxy the enhancements were not all that significant. These results are especially disappointing considering the large surface-to-volume ratio of CNTs compared to other fillers, including carbon fibers, and the effect this-in theorycan have on energy absorption mechanisms such nanotube debonding or pull-out [64]. Therefore, a careful future optimization of processing parameters such as nanotube dispersion at higher concentrations, nanotube alignment and localization, should lead to further improvements in mechanical properties of these multiscale composites.

\section{References}

[1] P. Ciselli, Z. Wang, and T. Peijs, "Reinforcing potential of carbon nanotubes in oriented polymer fibres," Materials Technology, vol. 22, no. 1, pp. 10-21, 2007.

[2] Z. Wang, P. Ciselli, and T. Peijs, "The extraordinary reinforcing efficiency of single-walled carbon nanotubes in oriented poly(vinyl alcohol) tapes," Nanotechnology, vol. 18, no. 45, Article ID 455709, 2007.

[3] F. H. Gojny, M. H. G. Wichmann, B. Fiedler, and K. Schulte, "Influence of different carbon nanotubes on the mechanical properties of epoxy matrix composites - a comparative study," Composites Science and Technology, vol. 65, no. 15-16, pp. 2300-2313, 2005.

[4] F. H. Gojny, M. H. G. Wichmann, U. Kopke, B. Fiedler, and K. Schulte, "Carbon nanotube-reinforced epoxy-composites: enhanced stiffness and fracture toughness at low nanotube content," Composites Science and Technology, vol. 64, no. 15, pp. 2363-2371, 2004.

[5] B. Fiedler, F. H. Gojny, M. H. G. Wichmann, M. C. M. Nolte, and K. Schulte, "Fundamental aspects of nano-reinforced composites," Composites Science and Technology, vol. 66, no. 16, pp. 3115-3125, 2006.

[6] B. Wetzel, P. Rosso, F. Haupert, and K. Friedrich, "Epoxy nanocomposites-fracture and toughening mechanisms," Engineering Fracture Mechanics, vol. 73, no. 16, pp. 2375-2398, 2006.
[7] J. H. Du, J. Bai, and H. M. Cheng, "The present status and key problems of carbon nanotube based polymer composites," Express Polymer Letters, vol. 1, no. 5, pp. 253-273, 2007.

[8] Y. X. Zhou, P. X. Wu, Z.-Y. Cheng, J. Ingram, and S. Jeelani, "Improvement in electrical, thermal and mechanical properties of epoxy by filling carbon nanotube," Express Polymer Letters, vol. 2, no. 1, pp. 40-48, 2008.

[9] J. Sandler, M. S. P. Shaffer, T. Prasse, W. Bauhofer, K. Schulte, and A. H. Windle, "Development of a dispersion process for carbon nanotubes in an epoxy matrix and the resulting electrical properties," Polymer, vol. 40, no. 21, pp. 5967-5971, 1999.

[10] J. K. W. Sandler, J. E. Kirk, I. A. Kinloch, M. S. P. Shaffer, and A. H. Windle, "Ultra-low electrical percolation threshold in carbon-nanotube-epoxy composites," Polymer, vol. 44, no. 19, pp. 5893-5899, 2003.

[11] R. Zhang, A. Dowden, H. Deng, M. Baxendale, and T. Peijs, "Conductive network formation in the melt of carbon nanotube/thermoplastic polyurethane composite," Composites Science and Technology, vol. 69, no. 10, pp. 1499-1504, 2009.

[12] R. Zhang, M. Baxendale, and T. Peijs, "Universal resistivitystrain dependence of carbon nanotube/polymer composites," Physical Review B, vol. 76, no. 19, Article ID 195433, 2007.

[13] F. Inam and T. Peijs, "Re-aggregation of carbon nanotubes in two-component epoxy system," Journal of Nanostructured Polymers and Nanocomposites, vol. 2, no. 3, pp. 87-95, 2006.

[14] F. Inam, H. Yan, D. D. Jayaseelan, T. Peijs, and M. J. Reece, "Electrically conductive alumina-carbon nanocomposites prepared by Spark Plasma Sintering," Journal of the European Ceramic Society, vol. 30, no. 2, pp. 153-157, 2010.

[15] A. A. J. M. Peijs, R. W. Venderbosch, and P. J. Lemstra, "Hybrid composites based on polyethylene and carbon fibres-part 3. Impact resistant structural composites through damage management," Composites, vol. 21, no. 6, pp. 522-530, 1990.

[16] A. A. J. M. Peijs and R. W. Venderbosch, "Hybrid composites based on polyethylene and carbon fibres Part IV Influence of hybrid design on impact strength," Journal of Materials Science Letters, vol. 10, no. 19, pp. 1122-1124, 1991.

[17] B. Schrauwen, P. Bertens, and T. Peijs, "Influence of hybridisation and test geometry on the impact response of glassfibre-reinforced laminated composites," Polymers and Polymer Composites, vol. 10, no. 4, pp. 259-272, 2002.

[18] P. Karapappas, A. Vavouliotis, P. Tsotra, V. Kostopoulos, and A. Paipetis, "Enhanced fracture properties of carbon reinforced composites by the addition of multi-wall carbon nanotubes," Journal of Composite Materials, vol. 43, no. 9, pp. 977-985, 2009.

[19] J. Njuguna, K. Pielichowski, and J. R. Alcock, "Epoxybased fiber reinforced nanocomposites," Advanced Engineering Materials, vol. 9, no. 10, pp. 835-847, 2007.

[20] T. Mahrholz, J. Mosch, D. Rostermundt, U. Riedel, L. Herbeck, and M. Sinapius, "Fiber-reinforced nanocomposites for spacecraft structures: manufacturing, characterization and application," in Proceedings of the European Conference on Spacecraft Structures, Materials and Mechanical Testing, pp. 1445-1454, 2005.

[21] G. Romhany and G. Szebenyi, "Interlaminar crack propagation in MWCNT/fiber reinforced hybrid composites," Express Polymer Letters, vol. 3, no. 3, pp. 145-151, 2009.

[22] C. Chen and D. Curliss, "Resin matrix composites: organoclay-aerospace epoxy nanocomposites-part 2," SAMPE Journal, vol. 37, no. 5, pp. 11-18, 2001. 
[23] B. P. Rice, C. Chen, L. Cloos, and D. Curliss, "Carbon fiber composites: organoclay-aerospace epoxy nanocompositespart 1," SAMPE Journal, vol. 37, no. 5, pp. 7-9, 2001.

[24] F. H. Gojny, M. H. G. Wichmann, B. Fiedler, W. Bauhofer, and K. Schulte, "Influence of nano-modification on the mechanical and electrical properties of conventional fibrereinforced composites," Composites Part A, vol. 36, no. 11, pp. 1525-1535, 2005.

[25] S. Tsantzalis, P. Karapappas, A. Vavouliotis, et al., "Enhancement of the mechanical performance of an epoxy resin and fiber reinforced epoxy resin composites by the introduction of CNF and PZT particles at the microscale," Composites Part A, vol. 38, no. 4, pp. 1076-1081, 2007.

[26] S. Tsantzalis, P. Karapappas, A. Vavouliotis, et al., "On the improvement of toughness of CFRPs with resin doped with CNF and PZT particles," Composites Part A, vol. 38, no. 4, pp. 1159-1162, 2007.

[27] M. H. G. Wichmann, J. Sumfleth, F. H. Gojny, M. Quaresimin, B. Fiedler, and K. Schulte, "Glass-fibre-reinforced composites with enhanced mechanical and electrical properties-benefits and limitations of a nanoparticle modified matrix," Engineering Fracture Mechanics, vol. 73, no. 16, pp. 2346-2359, 2006.

[28] F. H. Chowdhury, M. V. Hosur, and S. Jeelani, "Studies on the flexural and thermomechanical properties of woven carbon/nanoclay-epoxy laminates," Materials Science and Engineering A, vol. 421, no. 1-2, pp. 298-306, 2006.

[29] F. Hussain, D. Dean, A. Haque, and A. M. Shamsuzzoha, "S2 glass/vinylester polymer nanocomposites: manufacturing, structures, thermal and mechanical properties," Journal of Advanced Materials, vol. 37, no. 1, pp. 16-27, 2005.

[30] A. Haque, M. Shamsuzzoha, F. Hussain, and D. Dean, "S2-glass/epoxy polymer nanocomposites: manufacturing, structures, thermal and mechanical properties," Journal of Composite Materials, vol. 37, no. 20, pp. 1821-1838, 2003.

[31] T. Yokozeki, Y. Iwahori, and S. Ishiwata, "Matrix cracking behaviors in carbon fiber/epoxy laminates filled with cupstacked carbon nanotubes (CSCNTs)," Composites Part A, vol. 38, no. 3, pp. 917-924, 2007.

[32] J. Qiu, C. Zhang, B. Wang, and R. Liang, "Carbon nanotube integrated multifunctional multiscale composites," Nanotechnology, vol. 18, no. 27, Article ID 275708, 2007.

[33] E. T. Thostenson, W. Z. Li, D. Z. Wang, Z. F. Ren, and T. W. Chou, "Carbon nanotube/carbon fiber hybrid multiscale composites," Journal of Applied Physics, vol. 91, no. 9, pp. 6034-6037, 2002.

[34] K. L. Kepple, G. P. Sanborn, P. A. Lacasse, K. M. Gruenberg, and W. J. Ready, "Improved fracture toughness of carbon fiber composite functionalized with multi walled carbon nanotubes," Carbon, vol. 46, no. 15, pp. 2026-2033, 2008.

[35] J. Gou, W. Hollinghead, A. Whitaker, B. Sheffer, J. Foster, and D. Hui, "Processing of fiber reinforced composites with carbon nanofiber-modified matrix using resin transfer molding," in Proceedings of 11th International Conference on Composites/Nano Engineering (ICCE '04), SC, USA, August 2004.

[36] D. P. N. Vlasveld, W. Daud, H. E. N. Bersee, and S. J. Picken, "Continuous fibre composites with a nanocomposite matrix: improvement of flexural and compressive strength at elevated temperatures," Composites Part A, vol. 38, no. 3, pp. 730-738, 2007.

[37] D. P. N. Vlasveld, H. E. N. Bersee, and S. J. Picken, "Creep and physical aging behaviour of PA6 nanocomposites," Polymer, vol. 46, no. 26, pp. 12539-12545, 2005.
[38] M. A. V. Es, Polymer clay nanocomposites. The importance of particle dimensions, Ph.D. thesis, Delft University of Technology, The Netherlands, 2001.

[39] E. P. Giannelis, "Polymer layered silicate nanocomposites," Advanced Materials, vol. 8, no. 1, pp. 29-35, 1996.

[40] Y. Kojima, A. Usuki, M. Kawasumi, A. Okada, T. Kurauchi, and O. Kamigaito, "Sorption of water in nylon 6-clay hybrid," Journal of Applied Polymer Science, vol. 49, no. 7, pp. 12591264, 1993.

[41] H. L. Qin, Q. S. Su, S. M. Zhang, B. Zhao, and M. S. Yang, "Thermal stability and flammability of polyamide 66/montmorillonite nanocomposites," Polymer, vol. 44, no. 24, pp. 7533-7538, 2003.

[42] T. Kashiwagi, R. H. Harris Jr., X. Zhang, et al., "Flame retardant mechanism of polyamide 6-clay nanocomposites," Polymer, vol. 45, no. 3, pp. 881-891, 2004.

[43] L. Qu, Y. Zhao, and L. Dai, "Carbon microfibers sheathed with aligned carbon nanotubes: towards multidimensional, multicomponent, and multifunctional nanomaterials," Small, vol. 2, no. 8-9, pp. 1052-1059, 2006.

[44] S. J. V. Frankland, J. C. Riddick, and T. S. Gates, "Multiscale rule-of-mixtures model of carbon nanotube/carbon fiber/epoxy lamina," in Proceedings of the Materials Research Society Symposium, vol. 887, pp. 61-70, 2006.

[45] CYTEC Engineered Materials, CYCOM 823 Technical Data sheet, 2004.

[46] M. Cadek, J. N. Coleman, K. P. Ryan, et al., "Reinforcement of polymers with carbon nanotubes: the role of nanotube surface area," Nano Letters, vol. 4, no. 2, pp. 353-356, 2004.

[47] F. Inam and T. Peijs, "Transmission light microscopy of carbon nanotubes-epoxy nanocomposites involving different dispersion methods," Advanced Composites Letters, vol. 15, no. 1, pp. 7-13, 2006.

[48] ASTM, "Standard test methods for constituent content of composite materials," Annual Book of ASTM Standards, D 3171-99, 2004.

[49] E. T. Thostenson and T.-W. Chou, "Aligned multi-walled carbon nanotube-reinforced composites: processing and mechanical characterization," Journal of Physics D, vol. 35, no. 16, pp. L77-L80, 2002.

[50] E. T. Thostenson, C. Li, and T. W. Chou, "Nanocomposites in context," Composites Science and Technology, vol. 65, no. 3-4, pp. 491-516, 2005.

[51] D. Dean, A. M. Obore, S. Richmond, and E. Nyairo, "Multiscale fiber-reinforced nanocomposites: synthesis, processing and properties," Composites Science and Technology, vol. 66, no. 13, pp. 2135-2142, 2006.

[52] I. A. Guz and Ya. Ya. Rushchitskii, "Comparison of mechanical properties and effects in micro- and nanocomposites with carbon fillers (carbon microfibers, graphite microwhiskers, and carbon nanotubes)," Mechanics of Composite Materials, vol. 40, no. 3, pp. 179-190, 2004.

[53] M. B. Bryning, M. F. Islam, J. M. Kikkawa, and A. G. Yodh, "Very low conductivity threshold in bulk isotropic single-walled carbon nanotube-epoxy composites," Advanced Materials, vol. 17, no. 9, pp. 1186-1191, 2005.

[54] A. A. Mamedov, N. A. Kotov, M. Prato, D. M. Guldi, J. P. Wicksted, and A. Hirsch, "Molecular design of strong singlewall carbon nanotube/polyelectrolyte multilayer composites," Nature Materials, vol. 1, no. 3, pp. 190-194, 2002.

[55] B. Schrauwen and T. Peijs, "Influence of matrix ductility and fibre architecture on the repeated impact response of glassfibre-reinforced laminated composites," Applied Composite Materials, vol. 9, no. 6, pp. 331-352, 2002. 
[56] R. W. Venderbosch, T. Peijs, H. E. H. Meijer, and P. L. Lemstra, "Fibre-reinforced composites with tailored interphases using PPE/epoxy blends as a matrix system," Composites Part A, vol. 27, no. 9, pp. 895-905, 1996.

[57] H. Kishi, K. Uesawa, S. Matsuda, and A. Murakami, "Adhesive strength and mechanisms of epoxy resins toughened with preformed thermoplastic polymer particles," Journal of Adhesion Science and Technology, vol. 19, no. 15, pp. 1277-1290, 2005.

[58] Y. Liu, W. Zhang, and H. Zhou, "Mechanical properties of epoxy resin/hydroxyl-terminated polyester blends: effect of two-phase structure," Polymer International, vol. 54, no. 10, pp. 1408-1415, 2005.

[59] K.-C. Lee, H. H. Yu, S.-J. Hwang, Y.-S. Li, M.-H. Cheng, and C.-C. Lin, "Preparation and characterization of the modified carbon nanotubes enhanced epoxy resin composites," Materials Science Forum, vol. 505-507, pp. 1075-1080, 2006.

[60] S.-M. Yuen, M. Chen-Chi, H.-H. Wu, et al., "Preparation and thermal, electrical, and morphological properties of multiwalled carbon nanotube and epoxy composites," Journal of Applied Polymer Science, vol. 103, no. 2, pp. 1272-1278, 2007.

[61] L. R. Xu, V. Bhamidipati, W.-H. Zhong, et al., "Mechanical property characterization of a polymeric nanocomposite reinforced by graphitic nanofibers with reactive linkers," Journal of Composite Materials, vol. 38, no. 18, pp. 1563-1582, 2004.

[62] G. S. Zhuang, G. X. Sui, Z. S. Sun, and R. Yang, "Pseudo reinforcement effect of multiwalled carbon nanotubes in epoxy matrix composites," Journal of Applied Polymer Science, vol. 102, no. 4, pp. 3665-3672, 2006.

[63] A. Allaoui, S. Bai, H. M. Cheng, and J. B. Bai, "Mechanical and electrical properties of a MWNT/epoxy composite," Composites Science and Technology, vol. 62, no. 15, pp. 1993 1998, 2002.

[64] M. H. G. Wichmann, K. Schulte, and H. D. Wagner, "On nanocomposite toughness," Composites Science and Technology, vol. 68, no. 1, pp. 329-331, 2008. 

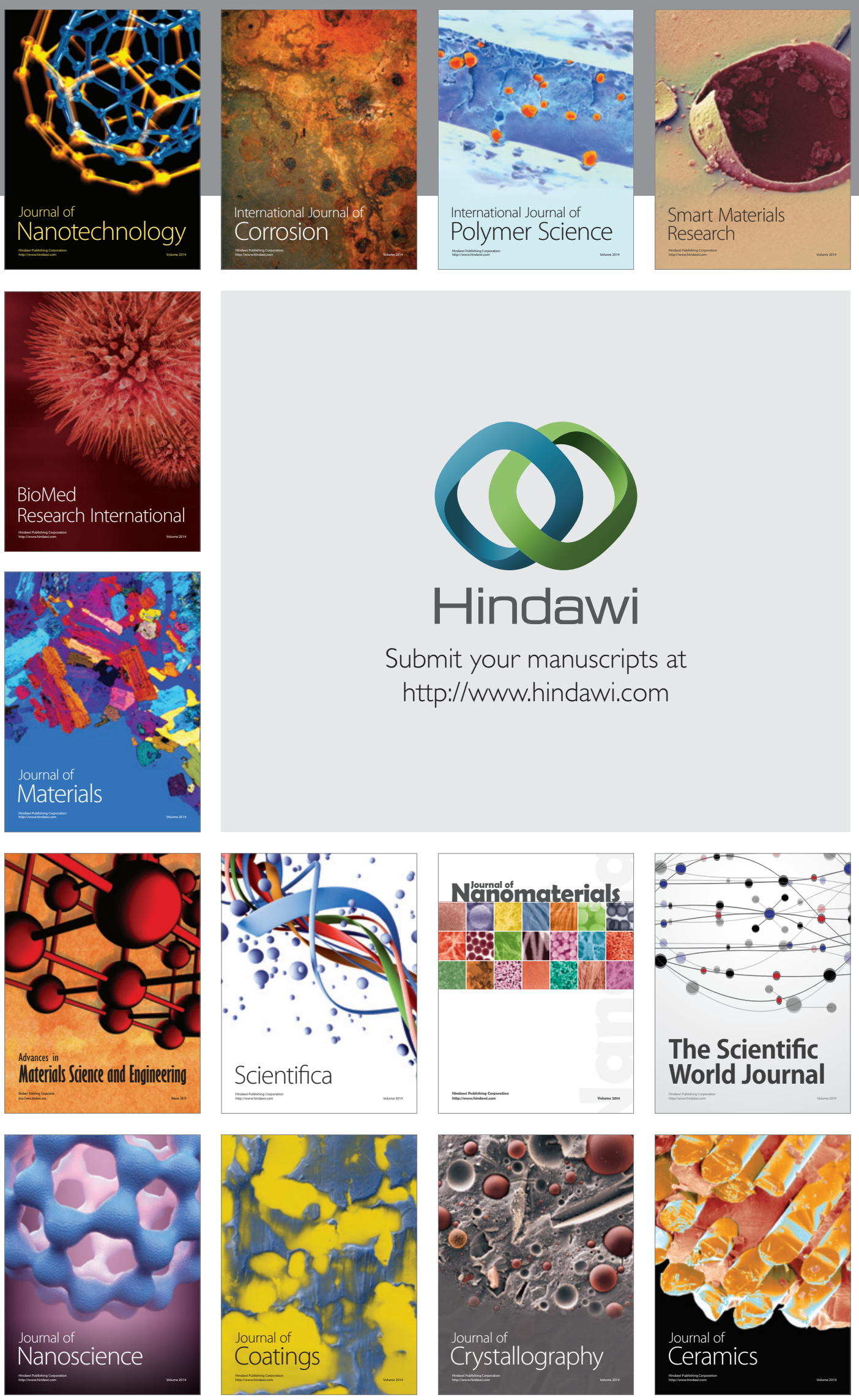

The Scientific World Journal

Submit your manuscripts at

http://www.hindawi.com

\section{World Journal}

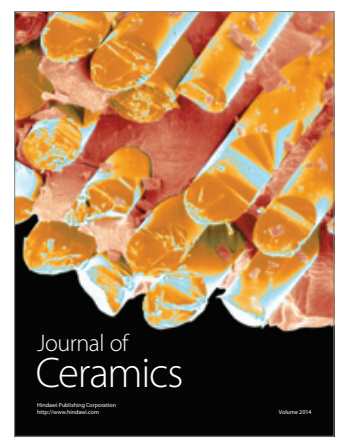

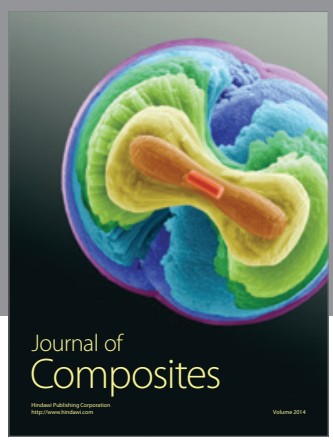
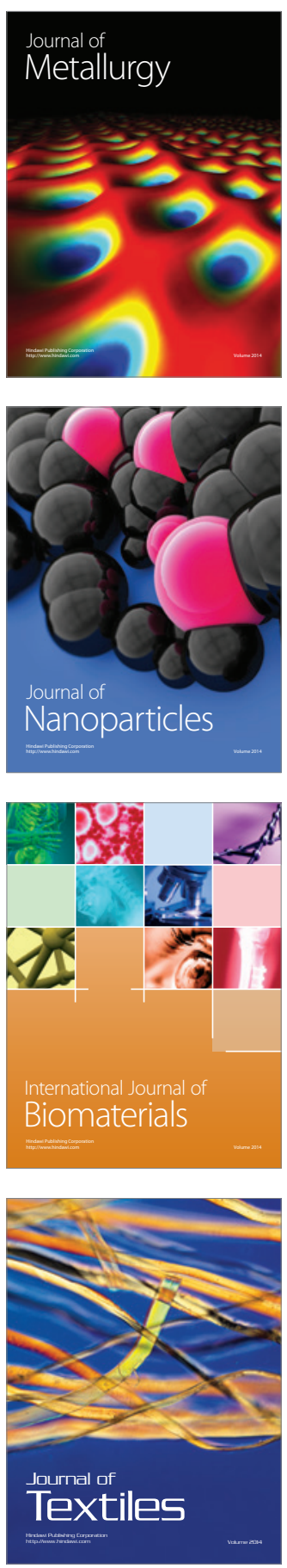